\title{
Mobility as a Service in Community Transport in Australia: can it provide a sustainable future?
}

Corinne Mulley, Chinh Ho, Camila Balbontin, David Hensher, Larissa Blewitt, John D Nelson and Steve Wright

Institute of Transport and Logistics Studies

The University of Sydney Business School

NSW 2006 Australia

Corinne.Mulley@sydney.edu.au

Chinh.Ho@sydney.edu.au

Camila.Balbontin@sydney.edu.au

David.Hensher@sydney.edu.au

Larissa.Blewitt@sydney.edu.au

j.d.nelson@abdn.ac.uk

s.d.wright@abdn.ac.uk

Version: 24 January 2019

\section{Abstract}

Mobility as a Service (MaaS) is seen as a transition from mobility being satisfied by a dominant car ownership model to a service model where mobility needs are met by a multimodal suite of services. The research environment of MaaS is heavily driven by the younger generation's travel behaviour which appears to be less dominated by car ownership (following the peak car literature) and by their interest in all things technological, particularly their smart phones. However, this paper is looking at a different but very specific segment of the population in Australia that have their accessibility provided by Community Transport (CT), focusing specifically on New South Wales (NSW) and Queensland (QLD). Arguably, this population segment is the complete antithesis of the younger generation in terms of chasing technological change but in other ways, for example, a lack of access to private cars, shows some similarities.

This paper is motivated by likely changes in funding for CT providers. Currently CT providers receive a supply side subsidy but there are plans to introduce funding to be placed directly with clients, in the form of person centred funding (PCF). Clients will then have a single budget to purchase mobility along with other services they require. The paper investigates the mobility services which comprise bundles that CT clients would be willing to pay in the new era of PCF. Five participating CT providers from a cross section of operating areas recruited clients to take part in a stated choice experiment, processed by a computer assisted personal interview (CAPI). Advanced choice models are used to develop models using the behavioural data collected by the CAPI and estimates of a CT client's 
willingness to pay (WTP) for the MaaS bundle are presented. WTP provides a ceiling for pricing the elements within a MaaS bundle which is an important part of the CT providers' future strategy. The WTP estimates were much smaller than the CT providers' unit costs of providing the service. This poses a challenge for CT providers in the creation of mobiltiy bundles which cover costs, suggesting that the possible transition to PCF using MaaS bundles will not be an easy process and will require significant education as to the cost of provision. The paper concludes with some suggestions as to how CT providers could make the transition to PCF building on the evidence of this research.

Keywords: Mobility as a service, community transport, Australia, choice experiment, willingness to pay

Acknowledgments: Funding sources: This paper utilised research funded under the University of Sydney Business School's Industry Partnership scheme whereby five CT providers partnered with the Business School to fund the research. The authors acknowledge the facilities, and the scientific and technical assistance of the Sydney Informatics Hub at the University of Sydney and, in particular, access to the high performance computing facility Artemis.

\section{Introduction}

The emergence of new shared mobility services, alongside traditional public transport, is resulting in a wider range of alternatives to private car use. However, in most cities, many of the newer sustainable transport modes operate in a largely unconnected fashion with separate tickets, payment, booking and mobile apps. This discourages many people from taking advantage of them. Mobility as a Service (MaaS) is a new approach to achieving collaboration and integration between transport providers and where a user (traveller) engages a single organisation to coordinate and facilitate their mobility needs (Hietanen, 2014). It can also be seen as the transition from the dominant car ownership model of satisfying mobility to an environment where mobility needs are met by a multimodal suite of services managed through a mobile device using subscriptions of mobility bundles (an analogy with the bundling of telecom services is often made). MaaS is widely regarded as having the potential to provide an attractive and convenient solution to help meet the mobility needs of those who either no longer want to own a car, cannot afford a car or cannot drive a car. To date, the MaaS concept has been largely driven by the societal and technological change discernible amongst the younger generation where the peak car phenomenon suggests the car ownership model is no longer dominant (see Goodwin \& Van Dender, 2013) and the high penetration of smart phones making this generation an ideal market segment to target the MaaS concept. 
This paper is not concerned with the younger generation but with a different and highly specific population segment of older people and their response to MaaS bundles. Arguably, this population segment could be seen as the complete antithesis of the younger generation discussed above in terms of mobile phone penetration but in other ways, for example, the lack of access to private cars in later life, shows some similarities. More specifically this paper is concerned with the segment of population in Australia who have their mobility provided by Community Transport (CT), focusing specifically on New South Wales (NSW) and Queensland (QLD). This paper thus extends the convincing case that can be made for MaaS amongst young adults in urban areas, where the majority of MaaS research and development is focused to date, to older adults aged over 65 in urban or suburban areas. The aim is to identify whether appropriately designed MaaS may offer improvements in the delivery of transport to these older citizens and whether this target segment would accept such bundles.

The original motivation for the research underpinning this paper came from a proposed funding change for CT providers in Australia. CT in Australia, in common with CT services in the United Kingdom (UK) and United States (US), provides subsidised services to the aged, frail, those with disabilities and, in some cases, people at risk of transport disadvantage. Although CT providers in different states in Australia have diverse subsidy arrangements, the CT providers in NSW and QLD are more similar in receiving a block grant which provides for an average subsidy for every mobility trip provided, with the clients of CT being asked for a contribution which is typically a small proportion of the actual cost of the service. The proposed funding change is to place all funding directly with clients, in the form of personcentred funding (PCF) allowing older people to have a single budget to purchase mobility along with a collection of other services that they may require (e.g. meals on wheels and cleaning services). The mobility that the PCF can be used to purchase can potentially be very similar to the recipient's current "consumption", whilst also offering the recipients a wider range of mobility service to choose from for different trips (e.g. conventional public transport, taxi, car share, volunteer car services etc.). Furthermore, the effect of moving funding from the service providers to the users is that eligibility constraints previously imposed on CT services which received funding are relaxed, opening up the service to non-eligible passengers as well.

The proposed funding change strikes at the heart of the way that CT is currently organised since they are currently committed to providing mobility for all who need it, irrespective of whether the requested trip is one which is relatively cheap or relatively expensive to provide. For example, this research revealed that group social outings for $\mathrm{CT}$ clients which is pre-booked is relatively inexpensive to provide (on a per head basis) compared to personalised medical trips, often requiring specialised equipment and 
significant time to allow the client to enter the vehicle. Yet the CT block funding model gives an average subsidy per trip. CT providers fear the potential future scenario whereby clients with PCF will seek only to purchase expensive trips from the CT provider and CT providers will be unable to practice the internal cross subsidisation they do currently. The research presented in this paper investigates the willingness to pay for a mobility bundle for trips currently provided by the CT provider and mobility options that the CT provider could provide as a broker or intermediary (taxi, car share, carpooling and public transport trips). The intention is to establish whether MaaS, in the form of a mobility bundle, offers the potential for the CT provider to have a sustainable future under a PCF regime by allowing a planning horizon through the pre-purchase of bundles which allow the continuation of internal cross subsidy as well as having the option to expand services into new client bases. From the client perspective, the investigation identifies whether MaaS bundle, if the client is willing to pay, can provide certainty about their mobility needs being met in the future.

The paper is structured as follows. The next section provides the literature context, in particular the travel needs and behaviour of older people as a background to the framing of the potential MaaS bundles of mobility for consideration in a stated choice (SC) experiment. This is followed by the method in which the case study context and the stated choice experiment are presented. The next section discusses the descriptive data results which underpin the choice of discrete model which is presented in the section which follows. The modelling results, including the estimation of willingness to pay by CT user's for elements of a MaaS bundle. The final section provides some discussion and conclusions as to how MaaS might be applicable (or not) in the context of CT providers and their clients in Australia.

\section{Literature context: The travel needs and behaviour of older people}

In most OECD (Organization for Economic Corporation and Development) countries the proportion of people aged 65 years or older is expected to increase by at least 50\% by 2050 (from 2010 levels) and the 'old-old' proportion of the population (those aged 80 years or more) is expected to at least double by 2050 (from 2010 levels) in most countries (Colombo, Ana, Jerome \& Frits, 2011); this is the cohort for whom current mobility opportunities are lowest. For Australia, between 2010 and 2050, the proportion of the population over 65 is expected to increase from $15 \%$ to $22 \%$, while those over 80 are expected to increase from around $4 \%$ to $8 \%$.

While the general trends of older persons travel activity is rather universal across developed nations, the specific parameters differ somewhat between countries due to e.g. differences in license renewal policies, bus subsidies and levels of provision, socio-economic or other background variables 
(Rosenbloom, 2001). It is clear that there is a need to distinguish between the "young" old and the "old" old: it is generally accepted in the literature spanning the last 20 years that the transition between "young" old and "old" old occurs somewhere between ages 75 and 80 (e.g. Siren \& Haustein 2012, Rosenbloom 2001, Suen \& Sen 2004), but as life expectancy increases and general health improves it is more likely that the transition will be closer to 80 .

The "young" old make, on average, over 3 trips per day which is a higher rate of trip making than people aged 20-59 (Age UK, 2012; Alsnih \& Hensher, 2006). Retirement brings a reduction in commuting trips but persons aged 60-69 make more shopping, personal business and leisure trips than the younger age groups. Whilst those over 70 make fewer trips overall, they make more shopping and personal business than those aged 50-59 (Mackett, 2014). A study conducted on data from Melbourne, Australia showed that trip-making did not drop substantially until over the age of 85 (Rosenbloom \& Morris, 1998). So even the "old" old are still making and desire to make several trips per day for shopping and personal business (social, health).

Regarding mode of travel, the "young" old are predominantly car drivers. In the USA 89 percent of older men (65+) are drivers, compared with 73 percent of older women (Lynott \& Figueiredo, 2009). In Denmark almost $95 \%$ of men and over $60 \%$ of women are car licence holders and for the most common trip purpose (shopping/service trips), 70\% of men aged 65-69 make these as car driver and $42 \%$ of women (Siren \& Haustein, 2012). By age 80-84 a significant change occurs, especially for women, when $57 \%$ of men aged $80-84$ are still driving for these trips but only $15 \%$ of women.

The level of public transport travel by older people appears to be universally low. In England, only a third of over 60's use the bus more than twice a month (notwithstanding a generous concessionary travel scheme for those at state pension age), while $43 \%$ claim to use it less than once a year or never (National Travel Survey, England, 2016 p.40). In the USA in 2009, 2.2\% of all trips were made by public transport by the over 65 age group and only $9 \%$ of trips by non-drivers over 65 were made by public transport (Lynott \& Figueiredo, 2011). In Denmark, the proportion of trips by public transport remains relatively low $(<5 \%)$ until age 75 when, although the take up by men is lower than women, it rises in stages to as much as $17.5 \%$ for women aged 80-84 (Siren \& Haustein, 2012). In Australia, analysis of data from almost 15,000 over 60 year olds in the Victorian Activity Travel Survey (VATS), (Transport Research Centre 1994-1999), revealed almost 7.5\% (0.21 trips per day) of trips made by over 60's were by public transport. For the over 75 age group this had increased to $9.25 \%$. So the data suggests that as large numbers of older persons approach 80 and reduce or stop driving, there is only a relatively small increase in public transport use. Rosenbloom (2009) argues there is little evidence to support the 
assertion that public transport will meet older adult mobility needs in lieu of their cars. Browning and Sims (2007) confirm this finding also relates to Australia stating: "in Australia driving is a key transport option for older people and as the baby boomer cohort ages the numbers of older drivers will increase. While many older people will continue to drive safely, a significant proportion of our older citizens will require alternate transport options especially as they move into their eighties and beyond when sensory and cognitive disability increase."

Since conventional public transport does not appear to be meeting the needs of the "old" old and driving is no longer an option for large proportions of this age group, more feasible alternative transport modes need to be available and accessible/affordable if adequate levels of mobility are to be maintained for those who cannot drive. The findings from a study of older persons travel in Brisbane suburbs suggest that it is critical to establish age-friendly means of transportation to enhance older people's engagement in all types of activities within their community (Zeitler \& Buys 2015). Community Transport currently offers a range of alternative age-friendly transport services for the old-old and frail citizens who cannot drive. As Mulley and Nelson (2012) point out, there are marked differences in the role of CT providers in North America and the UK in comparison to Australia. North American and the UK CT often provide community bus services to all members of the community in areas where no conventional public transport exists. In addition to this they tend to provide door-to-door shopping services and services to health and social care activities. CT in Australia is more targeted at the disabled and frail members of society as funding limits the ability of community transport groups to meet the spatial gaps inherent in the lower density land use of Australia, showing elements in common with other rural environments (Plazinic \& Jovic 2018).

An Australian study by Harris and Tapsas (2006) conducted a survey of 125 people 65+ who had recently ceased driving. They found that almost half found it difficult to adjust to no longer driving and felt disconnected and a further 21 percent found it particularly challenging, some because they were unable to use other forms of transport without assistance. The respondents mainly relied on taxis (82\%) or lifts from others (85\%), with much smaller proportions using public or community transport. While more than half the respondents were able to access buses, only half of those who had access would use them. Older people found taxis the easiest form of public transport to use, though problems associated with using taxis were being able to afford the fare and getting a taxi that would be able to do a very short trip. This illustrates the limited role of CT in Australia for those older persons who cease driving.

A recent study of a community-based response to meeting the needs of 'more difficult to reach' customers of public transport is found in Japan. In Japan, Uber penetrated the Tango area where the 
population is ageing along with depopulation (Nomura \& Takahashi, 2017). When conventional taxi operators abandoned operation the response was for Uber to be operated by a local non-governmental organisation, supported by local government (i.e. as a community-based NGO). This, like the exploration of MaaS CT discussed later in this paper, is a model that could be used to support rural communities. A related strand of discussion is whether providing more of a community based offering should link in to the public transport portfolio and if not, should it and what would need to be done to achieve this (Mulley \& Kronsell, 2018).

The changes to funding discussed in the introduction suggest that CT providers will be able to offer their services to a wider audience in the PCF world thus mirroring the way in which CT providers in the UK and North America provide services to all. This has the potential to widen their market to those older persons who cease driving, a population which is expected to double by 2050 with predicted growth in persons aged over 80 . While greater use of e-commerce amongst older persons is expected to reduce the need to travel for some trips, this will not replace the majority of trips (Shergold et al., 2015; Musselwhite, 2011). A study by the Transport Systems Catapult (2016) explored the relationship between older travellers and technology engagement (e.g. the use of smart phones), noting that the heterogeneity of older people (e.g. cognitive, physical) means they cannot be considered as one entity, but many older people will be able to handle new technology if given sufficient support and guidance. The use of participatory design techniques and an emphasis on ease of use can help ensure that older people are not excluded from accessing new technology.

From the CT provider perspective therefore, the subscription model of MaaS provides a mechanism to attract and lock-in their clients (and their PCF) to ensure a degree of certainty in revenue generation so as to fund the operation and management of the services they provide, and to also attract older persons who cease driving and are not be in receipt of PCF, but who are currently paying full fare for taxi trips. There are currently few studies which consider willingness to pay (WTP) for MaaS (Lyngby, Socher \& Sarasini, Ho et al., 2018), and no studies have been found which focus on older persons WTP for MaaS. In particular, it is clients who are unable to use conventional public transport and which require door-todoor services that are most likely to be entitled to receive PCF and to be the key clients of CT in Australia in the future. A MaaS CT solution thus needs to target older and frail citizens who cannot drive and are largely unable to use conventional public transport. Key to the potential success of MaaS CT is whether a subscription model can be identified that older people are willing to pay for (in most cases using their PCF budget) and can be priced at a level that allows CT providers to provide their service. 


\section{Method}

The research underpinning this paper is based on a stated choice (SC) experiment undertaken by a number of CT clients and non-users of CT services. The sample is drawn from the participating CT providers in the states of New South Wales (NSW) and Queensland (QLD) in Australia who joined in partnership with the University of Sydney to investigate this issue.

This section first describes case study context in terms of the participating CT providers, explaining their characteristics and that of their operating territory and the sample of respondents. This is followed by a description of the SC experiment in terms of the survey instrument and its implementation. The analysis of the experiment is the subject of the next section where the method underpinning the modelling is explained in detail following the presentation of the descriptive data results.

\section{The case study context}

This section describes the CT providers and the nature of the sample of respondents taking part in the stated choice experiment.

\section{The CT providers}

CT providers vary significantly in terms of their opportunities and appetite for entrepreneurial activity. Currently registered as 'not for profit' organisations, some CT providers are moving towards social entrepreneurship as a business model for the future whilst still relying on the current block funding model. The partners in this research all showed an appetite to become mobility providers being five of the more entrepreneurial CT providers representing the range of operating areas of urban, suburban and outer suburban operations in NSW and one provider covering multiple areas in QLD.

The five providers varied significantly in terms of the number of trips provided and the structure of their workforce (see Table 1). There was much more commonality in the number of vehicles although the structure of the fleets did vary, being different mixtures of cars, minibuses and small buses. Whilst the five providers were all partners and took part in discussions to identify the cost of provision of different services, only four were able to take part in the stated choice (SC) experiment - one of the outer suburban providers in NSW had operational issues at the time the experiment for the study was undertaken.

\section{Table 1: Characteristics of partner CT Providers.}




\begin{tabular}{|l|l|l|l|l|l|}
\hline & \multicolumn{2}{c}{ CT1 } & CT2 & CT3 & CT4 \\
\hline Service area & Inner city & Suburban & Mixed & Outer Suburban & Outer Suburban \\
\hline State of operation & NSW & NSW & QLD & NSW & NSW \\
\hline Trips per annum & 72,000 & 58,000 & 260,000 & 100,000 & 75,000 \\
\hline Paid staff (FTE) & 77 & 20 & 120 & 30 & 26 \\
\hline Volunteer staff & 0 & 100 & 300 & $30-40$ & 130 \\
\hline Vehicles & 27 & 20 & 50 & 29 & 25 \\
\hline
\end{tabular}

The basis of the research underpinning this paper is a SC experiment to examine the willingness to pay for mobility packages for the targeted segment of older people. For this, each CT provider was asked to recruit clients and non-users they believed would be willing to participate in the study. Nonusers, typically volunteers or residents of retirement villages, were included as these were seen as CT clients of the future but were in practice only a small percentage of respondents (7 percent). A Computer-Assisted Personal Interview (CAPI) involving trained interviewers from a third-party market research firm (Taverner Research) was employed to ensure that all respondents had the opportunity to have the survey explained, ask questions and feel comfortable with the survey content. The interviews were carried out in May and June 2017. The survey was administered in a face to face interview since examining willingness to pay for mobility with bundles is challenging as it involves hypothetical situations that the participants have no experience with.

\section{The sample}

Table 2 shows the profile of the participants to this study segmented by CT provider. In total, the final sample includes 105 usable interviews. The average age of the participants varies by CT with respondents' age ranging between 53 to 92 years old, except for one CT provider which contributes two young participants (26 and 35 years old, both already using CT services as disabled users).

Most of the participants are women and were born in Australia, except for one provider where the vast majority (96\%) of participants were born overseas (mainly in Asia). It is worth noting the differences in the current living arrangement of the participants across the participating CTs. In particular, most CT3 and CT4 participants are either living alone or in a retirement village whilst a majority of the CT1 and CT2 participants are living with someone, either their partner or their family/friends. The observed difference in living arrangement across $\mathrm{CT}$ regions may suggest different levels of support that the 
participants (i.e., current CT users) may get from their partners, friends or family members, both for transport and personal needs, having a knock-on effect for their requirements from CT.

Regarding mobility status, most respondents are still mobile and can walk up to 400 metres or further but there are ten participants who cannot walk at all and another four who can only walk up to 100 metres. Of the 10 participants who are very frail, six are currently using CT3 and four using CT1 and CT2 services (two each). A few participants (four or five in each CTs) hold a driver licence and have access to a car. This is in line with the small percentage of participants who can walk over 800 metres. This participant profile emphasises not only the lack of physical mobility in those around 70 years of age, but also the inability of around half of the respondents to drive themselves or use public transport to the places they need to go. Further, this highlights not only the importance of this research, but also the underlying need for older people to feel confident in managing and implementing their own transport needs.

Table 1: Profile of the participants to the MaaS-CT study

\begin{tabular}{|c|c|c|c|c|}
\hline & \multicolumn{4}{|c|}{ Community Transport } \\
\hline & CT1 & $\mathrm{CT} 2$ & CT3 & CT4 \\
\hline Number of participants who are non-user of CT & 3 & 4 & 0 & 0 \\
\hline Average age of participant (years) & 70.6 & 71.4 & 79.8 & 72.0 \\
\hline Percent participants who were born in Australia (\%) & 4 & 81 & 62 & 77 \\
\hline Percent male participants (\%) & 27 & 44 & 16 & 12 \\
\hline Percent participants holds driver licence (\%) & 31 & 38 & 16 & 23 \\
\hline Percent participants has access to car (\%) & 19 & 25 & 14 & 15 \\
\hline \multicolumn{5}{|l|}{ Living arrangement } \\
\hline living alone (\%) & 27 & 31 & 41 & 50 \\
\hline living with partner (\%) & 54 & 31 & 8 & 8 \\
\hline living with family/friends (\%) & 19 & 25 & 11 & 19 \\
\hline living in retirement village (\%) & 0 & 13 & 41 & 23 \\
\hline \multicolumn{5}{|l|}{ Marital status } \\
\hline single (\%) & 15 & 13 & 5 & 12 \\
\hline married (\%) & 62 & 38 & 16 & 15 \\
\hline widowed (\%) & 19 & 38 & 68 & 58 \\
\hline divorced (\%) & 4 & 13 & 8 & 12 \\
\hline de facto (\%) & 0 & 0 & 0 & 4 \\
\hline \multicolumn{5}{|l|}{ Walking ability } \\
\hline cannot walk at all (\%) & 8 & 0 & 16 & 8 \\
\hline can walk up to 100 metres (\%) & 0 & 6 & 0 & 12 \\
\hline can walk up to 400 metres (\%) & 19 & 38 & 27 & 31 \\
\hline can walk up to 800 metres (\%) & 54 & 31 & 24 & 4 \\
\hline can walk over 800 metres (\%) & 19 & 25 & 32 & 46 \\
\hline Sample size (number of participants) & 26 & 16 & 37 & 26 \\
\hline
\end{tabular}




\section{The Stated choice experiment}

This section first gives an outline of how the experiment was undertaken before introducing in some detail the survey instrument.

\section{The stated choice experiment}

As identified above, the willingness to pay for mobility bundles for the targeted segment is examined in a SC experiment, which is an established methodology for estimating the demand for new products such as MaaS.

Before doing the choice experiment the respondent was introduced to the concept of MaaS and its context. Respondents were informed that there could be changes to the funding regime that currently supports the provision of $\mathrm{CT}$, although at the time when the interviews were conducted, this possibility was very uncertain. The interviewers explained the change to PCF and reiterated that CT providers would still help organise travel and provide transport options but any user would have to pay the full fare with the subsidy coming separately as part of the PCF package. The packaging of mobility services was explained as a way in which CT providers could help the transition from the status quo to the new PCF environment.

\section{The survey instrument}

A survey instrument was programmed to be accessible via a computer connected to the Internet using any web-browser. In the experiment, respondents are given mobility options pivoting around the current travel behaviour reported for the two weeks prior to the experiment. Basing the choices around current experience offers choices that are more meaningful and comprehensible to respondents.

The online survey has five parts. The first part seeks respondent's mobility with questions pertaining to the respondent's ability to drive, access to car as a driver, walking capabilities, together with sociodemographics such as age, gender, marital status, living arrangements, and home postcode. The second part asks the respondent to report their travel patterns for a typical fortnight in terms of different activities undertaken (shopping, social outing, GP/dental, hospital, visit friends/family or volunteering), number of times these trips were made., the mode of travel for each reported activity type (community transport, bus, train, taxi, walk, light rail, ferry, drive or got a lift from friends/family member), distance from home, and the transport cost/fare. The respondent's responses to these questions were used to estimate their current travel demand for a typical fortnight so that customised MaaS bundles could be generated and used in the SC experiment. The final three parts of the survey were the choice experiments for the respondents. 
The first choice screen showed two hypothetical scenarios to the respondent, each of these offered two customised monthly mobility plans based on the respondent's current travel record. The respondent was asked to indicate if they would subscribe to the MaaS plan as an on-going user (first option) or pay as they go (PAYG) as the second option, or neither of these, in which case they would arrange their own travel under the proposed PCF. The response of subscription as an on-going plan is the MaaS option whereby mobility options are bundled together as the MaaS plan: it should be noted as shown in Figure 1 that the mobility plan offered options of accessibility (e.g. social trip, medical trip) where the mode is not specified as well as the 'emergency taxi' which is mode specific. The second option, PAYG, requires the client or user to sign up as a mobility user but instead of purchasing a bundle, the client would pay per trip taken but this would be at the subsidized price. If neither of the mobility options was selected, the interviewer ensured that the respondent understood that they would need to arrange their own travel independently whether by taxi or by a CT provider but this would be at a full fare since subsidised fare would be no longer available in this scenario. In the last choice task, respondents were offered a chance to create their own mobility plan and the survey instrument which was then priced it based on unit cost, established through separate discussions, for their participating CT provider. Finally, each respondent faced three options for the MaaS plan they created: subscribe as an on-going basis to receive discount, or PAYG (no discount) or arrange their own travel. Figure 1 provides an illustrative choice screen for a current CT user who reported using the shopping bus twice a month and attending social outings four times a month. 


\section{Your Mobility Plan: Scenario 1}

Given your travel record summarised in Column 1, we recommend you a Mobility Plan in Column 2, together with a Pay-As-You-Go Option for you to consider.

We would like you to compare and choose one of these options.

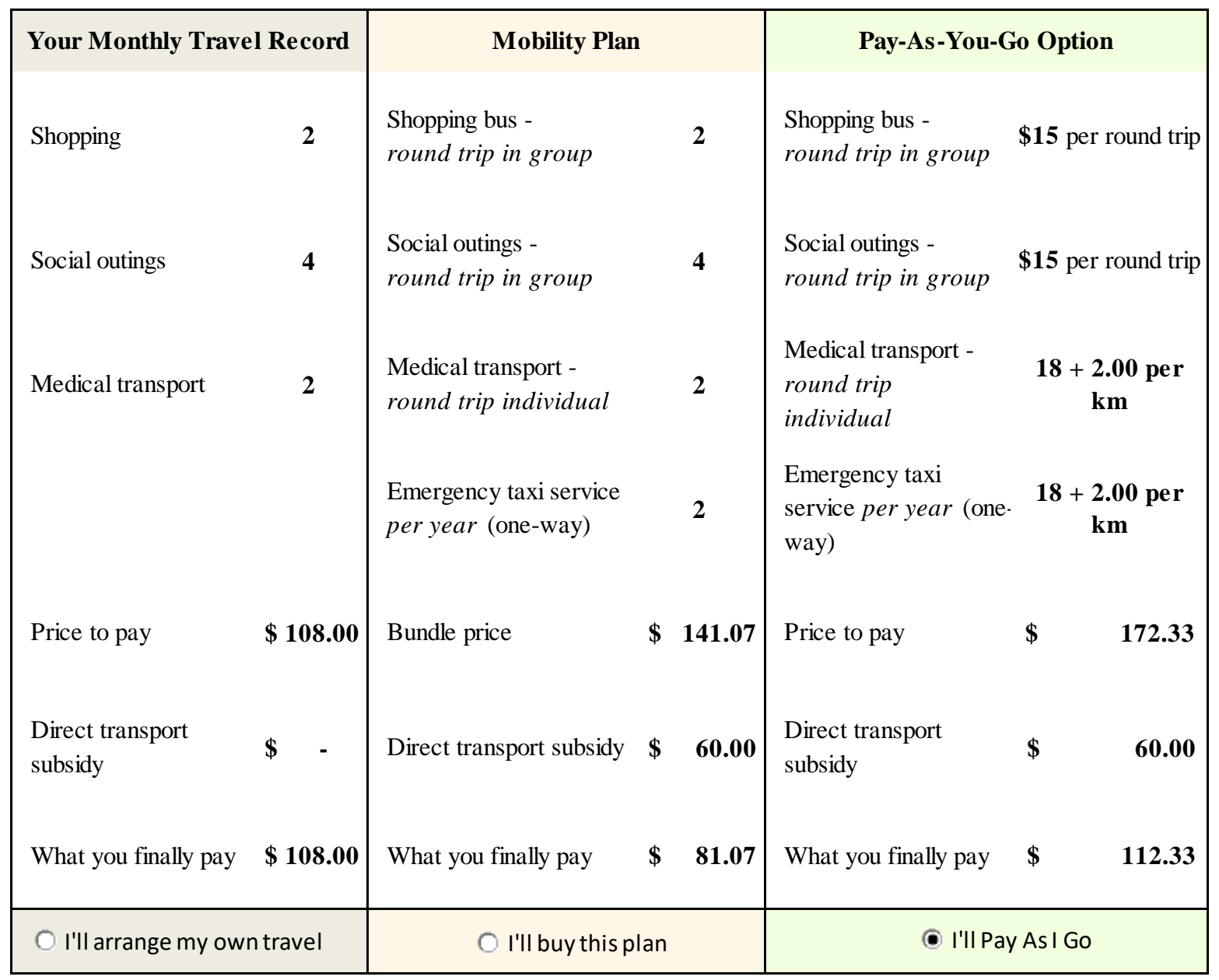

Figure 1: Your Customised Mobility Package

Sitting behind the SC experiment are three D-efficient designs (see Hensher, Rose \& Greene, 2015) of which one was assigned to the respondent based on their mobility status whether they are identified as being mobile aged (outings more than four times and seeing doctor/GP twice or less per month), active aged (outings less than four times per month and seeing doctor/GP twice or less per month), or frail aged (seeing doctor/GP more than twice per month). The designs were optimised using Ngene (Choice Metrics, 2012) for a sample comprising of 40 percent people classified as mobile, 40 percent active and 20 percent frail. The reference and pilot levels for each attribute entering the choice experiment are provided in Table 3. In summary, we use a so-called heterogenous pivot design, also 
known as stakeholder-specific design (see e.g., Rose and Bliemer, 2006 and Gatta et al. 2016), to generate different designs for different respondent segments based on the fact that different groups of CT users require different mobility needs (i.e., reference attributes) to get around and do their daily activities. A multi-stage efficient design (see for example Hensher et al, 2016 and Gatta et al., 2016) could have been layered on top to improve the efficiency of this heterogenous pivot design; however, given that the field work includes only four participating CTs, each with a small number of respondents (see Table 1), the cost of implementing multi-stage efficient designs was deemed not to provide sufficient potential gains in efficiency of data collection because having a few more respondents would, at the margin, have only a small effect on the standard errors of the parameter estimates (Rose \& Bliemer, 2013).

The design includes six choice tasks for each group of users, blocked into three sets of two choice tasks. The design attributes were pivoted off the current travel record of each respondent in real time (i.e. when the respondent did the survey) but the reference levels (first number in the last column of Table 3) are required to optimise the design. In other words, the choice tasks are customised to each respondent with an average value for a given segment only used to come up with an optimal pivoting rule for each attribute. For example, supposing that there are two people, both reporting to see their GP three times a month, go shopping twice a month but one person socialises once a month while the other person socialises three times in a month. Both people are classified as "frail", according to the design rule in Table 3. Supposing further that the same pivot levels of $(-2,0,0)$ are used for (medical, shopping, social) trips of these two people. This means they will see different mobility bundles with the first person having three social trips while the second person having one social trip (both have one medical trip and two shopping trips in a month for this pivoting rule). In a similar way, the cost levels are computed in real time based on the number of trips included in the mobility bundle, the percentage discount generated by the optimal design, and the unit cost provided by each CT provider. 
Table 3: Attribute levels of the stated choice experiment and assignment rules

\begin{tabular}{|c|c|c|}
\hline $\begin{array}{l}\text { Assigned to respondent } \\
\text { classified as }\end{array}$ & Attribute & $\begin{array}{l}\text { Attribute level } \\
\text { [Reference: Pivot level] }\end{array}$ \\
\hline \multirow{4}{*}{$\begin{array}{l}\text { Frail (see doctor/GP twice } \\
\text { or more per month) }\end{array}$} & Shopping bus & {$[2: 0,2]$} \\
\hline & Social outings & {$[2: 0,2]$} \\
\hline & Medical transport & {$[6: 0,-2]$} \\
\hline & Emergency taxi service & {$[4: 0,-2,-4]$} \\
\hline \multirow{4}{*}{$\begin{array}{l}\text { Active (outings less than } \\
\text { four times and seeing } \\
\text { doctor/GP twice or less } \\
\text { per month) }\end{array}$} & Shopping bus & {$[2: 0,2]$} \\
\hline & Social outings & {$[4: 0,2,4]$} \\
\hline & Medical transport & {$[0: 0,1]$} \\
\hline & Emergency taxi service & {$[4:-1,0,2]$} \\
\hline \multirow{4}{*}{$\begin{array}{l}\text { Mobile (outings more } \\
\text { than four times and } \\
\text { seeing doctor/GP twice or } \\
\text { less per month) }\end{array}$} & Shopping bus & {$[2: 0,2]$} \\
\hline & Social outings & {$[8: 0,-4,-6]$} \\
\hline & Medical transport & {$[1: 0,1]$} \\
\hline & Emergency taxi service & {$[1: 0,1,3]$} \\
\hline All respondents & Bundle discount (cf. unit cost) & [0: $-10 \%,-15 \%,-20 \%]$ \\
\hline
\end{tabular}

\section{Descriptive Statistics Results}

This section identifies the transport needs of the current CT users, as shown by the reported travel patterns over the two weeks before the survey date by the respondents. Seven non-user participants were removed from this analysis leaving a sample size of 98 users. The analysis provides a focus on the activity types the CT users undertake, how often they undertake these activities, and what transport modes they use to get to the last activity. These pieces of information are useful for understanding the basic transport needs and providing appropriate transport services to the current CT users.

\section{The respondents' activities in the previous two weeks}

Figure 2 presents the most popular types of activity undertaken by the sampled CT users, segmented by the number of activity types conducted in two weeks prior to the survey date. Of the 98 CT users, seven undertook only one activity type (see $\mathrm{N}=7$ in the first panel) whilst 11 conducted five activity types with most participants doing two to four types of activity in the two weeks prior to the interview date (see the texts in each panel). Regardless of the number of activity types undertaken, the most popular activities are shopping (i.e., the shopping bars are lengthiest in each panel), followed by social outings and medical check-ups (seeing doctor/dentist or visiting hospital). However, amongst the current CT users who did three or more different activity types in the two weeks before the survey (the last three panels of Figure 2), visiting friends/family is also popular which accounts for $14 \%$ to $22 \%$. This confirms the basic transport needs of the elderly for going shopping, social outings, and medical checkups. 


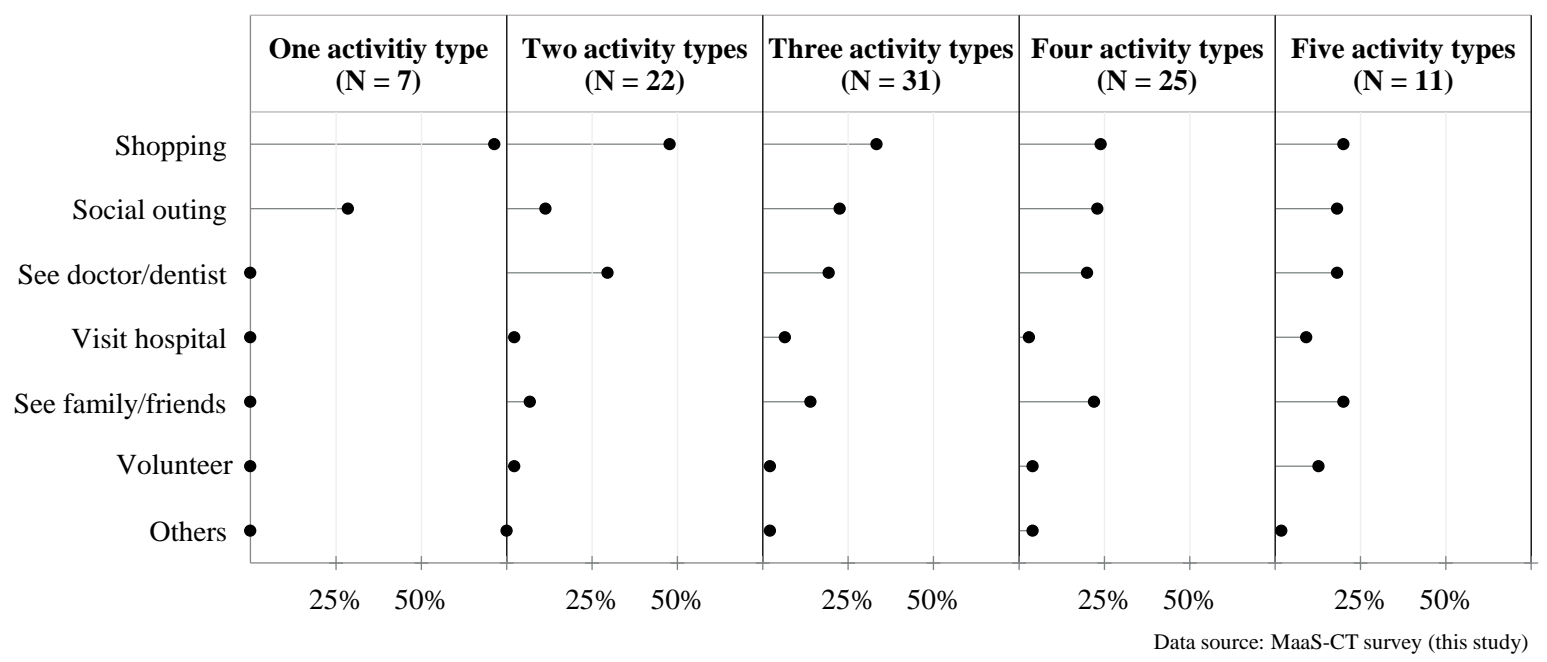

Figure 2: Share of activity type by number of activities undertaken in the last two weeks

Following the same grammar of graphics used in Figure 2, Figure 3 shows the number of times the same type of activity was undertaken by the sampled CT users over the period of two weeks. Of the 98 respondents participating in this survey, almost all went shopping in this period with a majority going once or twice per fortnight (i.e., the dot representing a "zero time per fortnight" is close to $0 \%$ ). This confirms the importance of providing a transport solution for older people to go shopping at least once per fortnight. Regarding social outings (second panel), about one third (37\%) of the sampled CT users did not report any social activity (top dot) over this period while more than half of the CT users participated in social outings one to three times per fortnight. For trips with a medical purpose, about one third of the CT users said that they did not see a doctor/dentist or visit a hospital over the two weeks before the survey whilst another third went once and the remaining third went twice or more. The frequency of different activities reported by the CT users (see Figure 3) justifies the reference levels used in the design of the MaaS bundles (see Table 3).

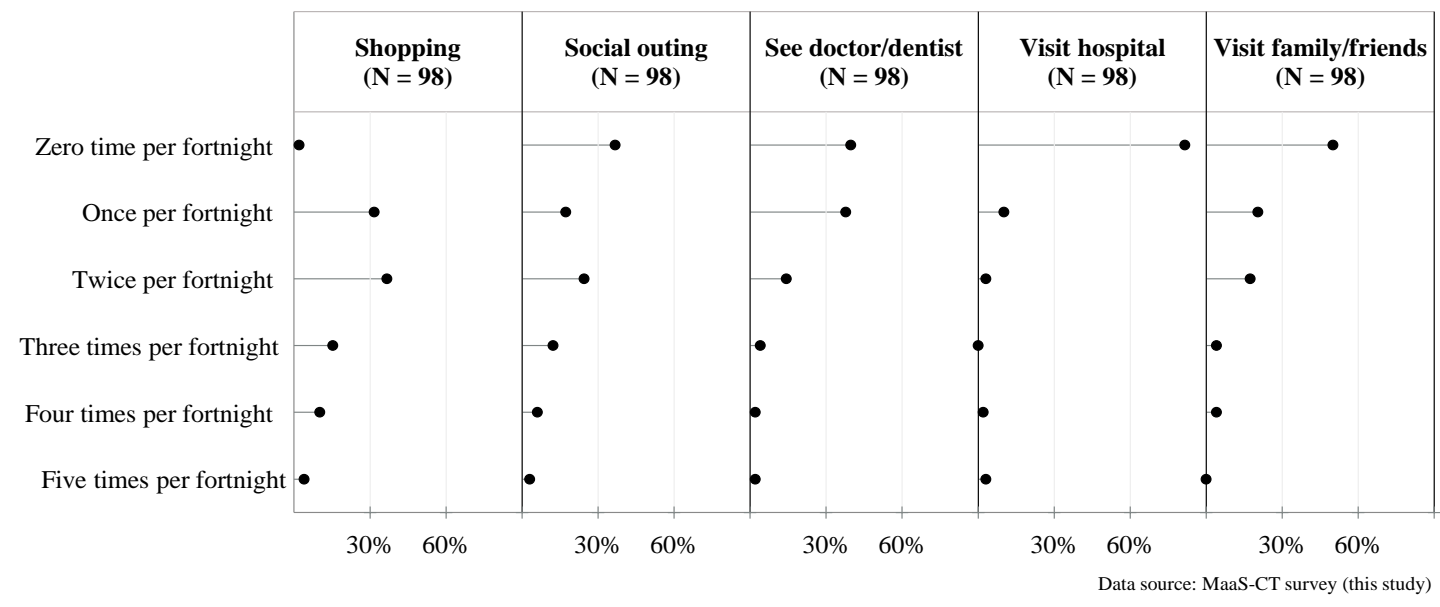


Figure 3: How often CT users undertakes different activity types

\section{Mode of travel for recent activities}

One concern relating to the proposed change of the CT funding model is whether CT providers will end up providing the more expensive trips to supply such as medical trips whilst more easy-to-serve trips such as group shopping and social outings would be arranged by the current CT users themselves using perhaps friends and relatives and so the CT providers would lose the ability to cross subsidise between the different types of trip. Figure 4 examines the ways in which the sampled CT users identified how they travelled for their 'last activity'. It appears that CT users currently rely on CT for doing most of their activities, except for visiting family and friends where the share of CT is much smaller. Under the current block funding model, there is not much difference in the CT user's choice of transport modes for the three most popular activity types (i.e., going shopping, social outings, and seeing a doctor/dentist). With a change to PCF, current CT users will only be able to maintain the same travel patterns if the travel budget allowance within the PCF covers the subsidy free costs of the CT provider service.

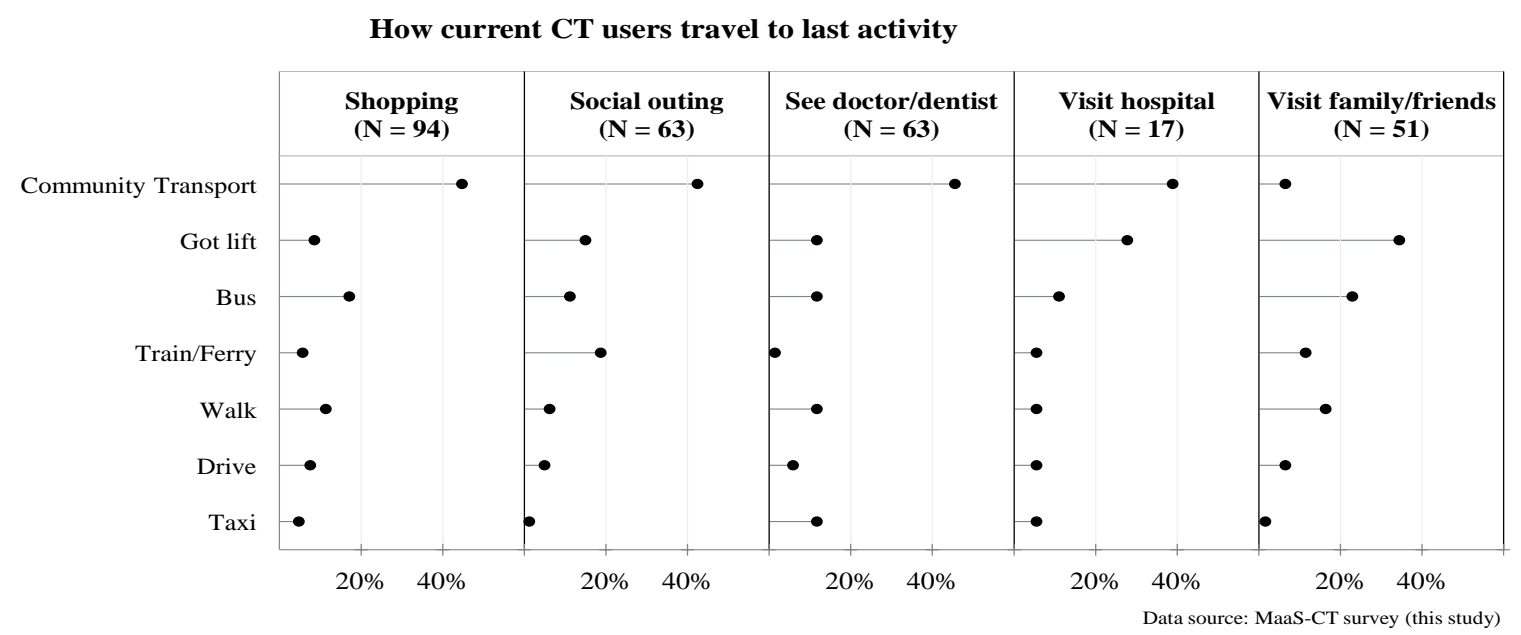

\section{Figure 4: Travel by CT users to 'last activity'}

The number and type and number of activities the respondents currently do can be compared with the experimental outcome suggesting what respondents might choose to be included in the MaaS package if PCF replaces the current funding model. Figure 5 shows the change in number of activities by type, segmented by CT provider. A zero value on the horizontal axis means that current CT users would not change any monthly activity while a negative value on the same axis means that current CT users would reduce the number of activities of that type. Values on the vertical axis indicate the number of respondents changing the frequency of their activities, by CT provider. Figure 5 suggests that current CT respondents would tend to reduce the number of shopping and social activities while maintaining the same number of medical trips, especially those respondents from CT1, CT2 and CT3 suggesting CT 
provider characteristics are not so important in this context. Given the share of CT trips amongst the respondents are quite similar across shopping, social outings and medical (see Figure 3), Figure 5 lends support to the concern that under a proposed PCF scheme, CT providers may end up providing more services for medical purposes which are relatively expensive, given the required support at either end of the trips (getting the passenger onto a CT bus/taxi and handing them over to someone at the medical centre/hospital). Group trips are mainly cheaper (per person) because there is a 'group' of travellers using them. If the group size diminishes then the cost per person increases. This creates big uncertainty for CT providers under the PCF model where users can choose where to spend their subsidy e.g. using PCF subsidy to partly pay for taxi to shopping trips.

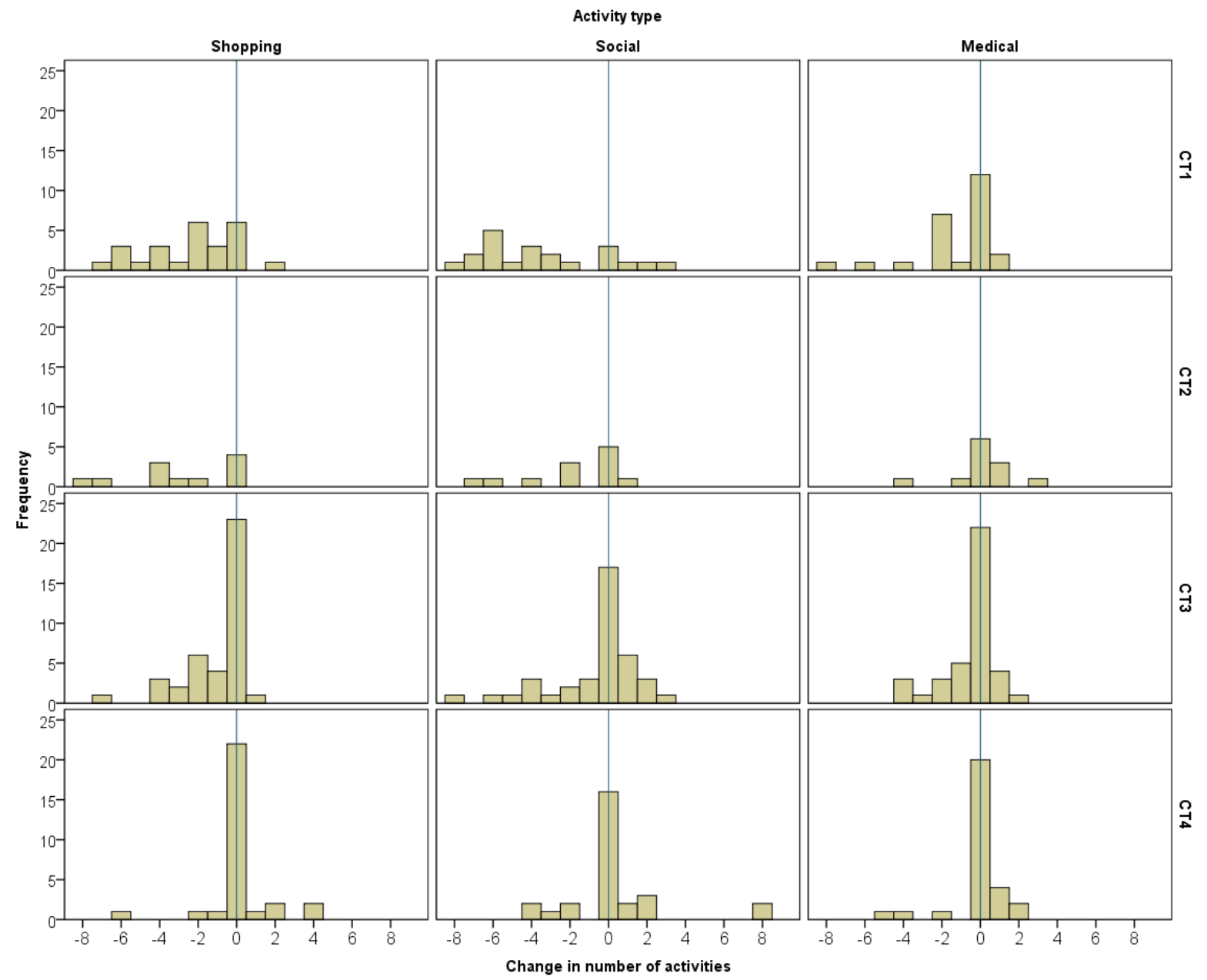

9

Figure 5: Number of activities respondents would include in MaaS monthly plan vs. current travel record

\section{Modelling of CT user's willingness to pay for MaaS plan}

In this section, the SC data and discrete choice modelling methods are used to estimate the CT user's willingness to pay for MaaS. Apart from the exercise where the respondent creates their own 
MaaS plan, the experiment offered two further choice scenarios, each as a pre-defined MaaS package where respondents were asked to choose one amongst the three options of arranging their own travel, subscribing to the pre-defined MaaS plan, or PayG.

\section{Choice of travel under PCF outcome}

Most individuals chose to arrange their own travel under a PCF outcome. Table 4 shows the split of options selected by respondents from the different CT providers. In CT1 and CT3 almost all users chose to arrange their own travel under the hypothetical scenario of PCF. Users of CT2 and CT4 are more likely to take up MaaS packages than their counterparts in CT1 and CT3. The PAYG option is rarely selected, suggesting that $\mathrm{CT}$ users would prefer discounts associated with MaaS plan to the flexibility associated with the PayG option.

Table 4: Choices by Community Transport Users

\begin{tabular}{lcccc}
\hline & CT1 & CT2 & CT3 & CT4 \\
\hline Arrange own travel & $70(90 \%)$ & $21(58 \%)$ & $96(80 \%)$ & $32(36 \%)$ \\
Subscribe to MaaS & $8(10 \%)$ & $13(36 \%)$ & $22(18 \%)$ & $51(57 \%)$ \\
PayG & $0(0 \%)$ & $2(6 \%)$ & $2(2 \%)$ & $7(8 \%)$ \\
Total & $78(100 \%)$ & $36(100 \%)$ & $129(100 \%)$ & $90(100 \%)$ \\
\hline
\end{tabular}

The next question is then whether offering the respondents the option of creating their own MaaS plan would increase their likelihood of subscribing. Figure 6 examines this by comparing the percentages of respondents who would take up MaaS offers when the mobility plans are pre-defined based on the respondent's travel record vs. when these plan are created by the respondents themselves. It is evidenced that if CT users could package their travel needs into a MaaS plan, the likelihood of subscription to MaaS would be higher, especially for CT1 and CT3 where the unit costs are relatively higher than the other two CT providers. For example, only $10 \%$ of the CT3 respondents would buy-in to the pre-defined MaaS plans tailored to their needs while this percentage increases to $35 \%$ if they package their monthly mobility plans (see CT3 panel, middle bars). 


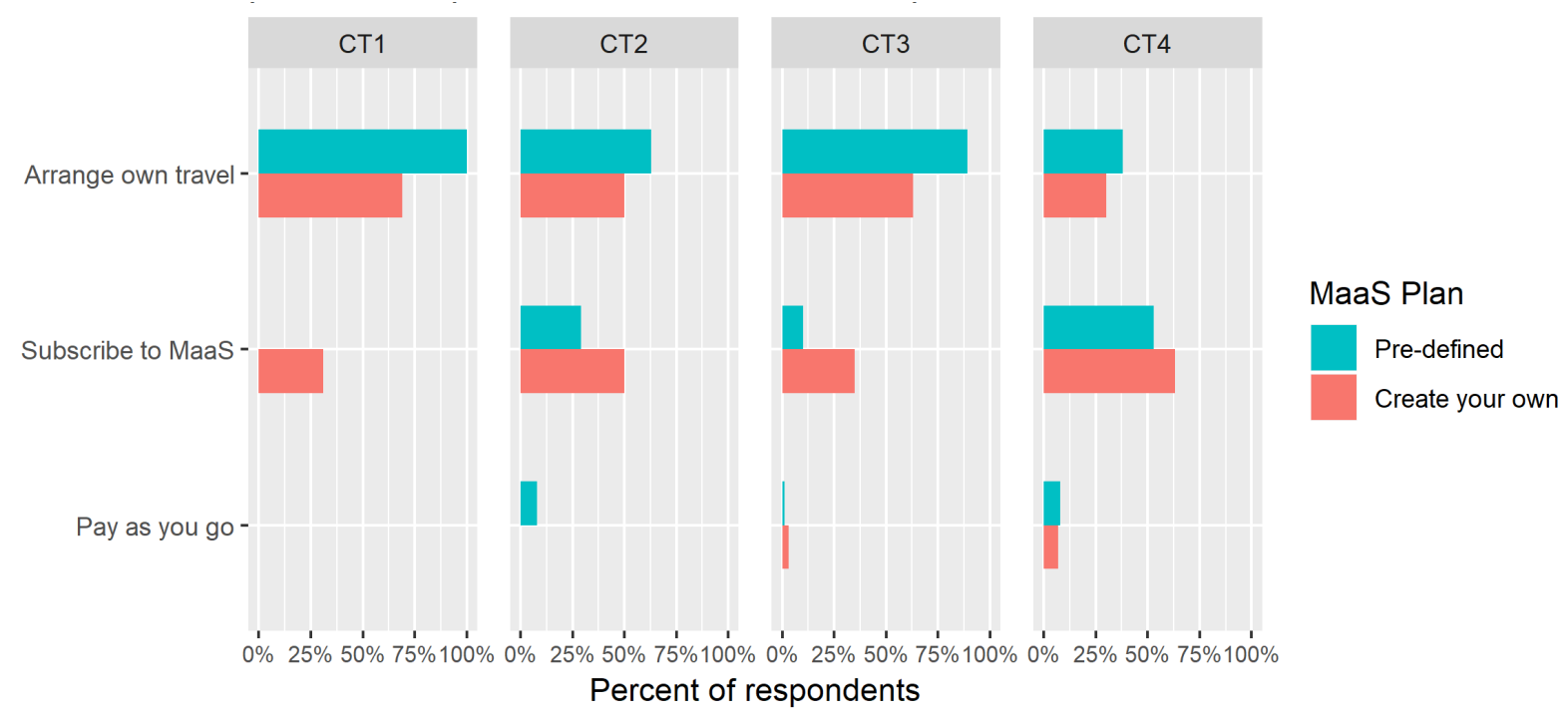

Figure 6: CT User's uptake of MaaS: pre-defined plan vs. 'Create Your Own' plan

Figure 5 above showed how respondents might respond to PCF introduction and suggests that many CT users would want to maintain their current level of activities suggesting a degree of habit. Generally, habit means that individuals replicate their current travel patterns rather than altering activity number or activity type. Error! Reference source not found. below shows the percentage of respondents that maintained the current trip numbers when they were provided an opportunity to create their own mobility plan. These people are exhibiting a habitual behaviour. Error! Reference source not found., bottom panels shows that across all CTs, $21 \%$ of respondents would keep their trips exactly the same but this habitual behaviour varies by CT ( $37 \%$ of CT 4 users, $23 \%$ of CT 3 users, $13 \%$ of CT 2 users, and $7 \%$ of CT1 users). It would seem that CT3 users are more likely to keep their trip pattern constant (highest percentage of 'same' trips, Error! Reference source not found., bottom panels), in contrast to CT1 users who most unlikely to keep them constant (lowest percentage of 'same' trips, Error! Reference source not found., bottom panels). There is small percentages of respondents across all CTs that increased their trip numbers (Figure 6, middle panels) and this is mainly for medical purposes. For medical purposes, $17 \%$ of respondents overall increase the number of medical trips (Error! Reference source not found., middle panel, first block) and specifically, of all the CTs, CT2 had the highest percentage - at 38\% - of users increasing their medical trips. A large percentage of respondents stated that they would decrease their trips (Error! Reference source not found., top panels). Overall, 17\% of all respondents decrease their total trips (Error! Reference source not found., top panel, first block) but this shows variation with decreases of $3 \%$ for CT4 users, $15 \%$ of CT3 users, $19 \%$ of CT2 users, and $31 \%$ of CT1 users. Across all CTs, $59 \%$ of respondents decrease their shopping trips again with variation between the CTs with $76 \%$ of CT1 users, 

users decrease their social trips.

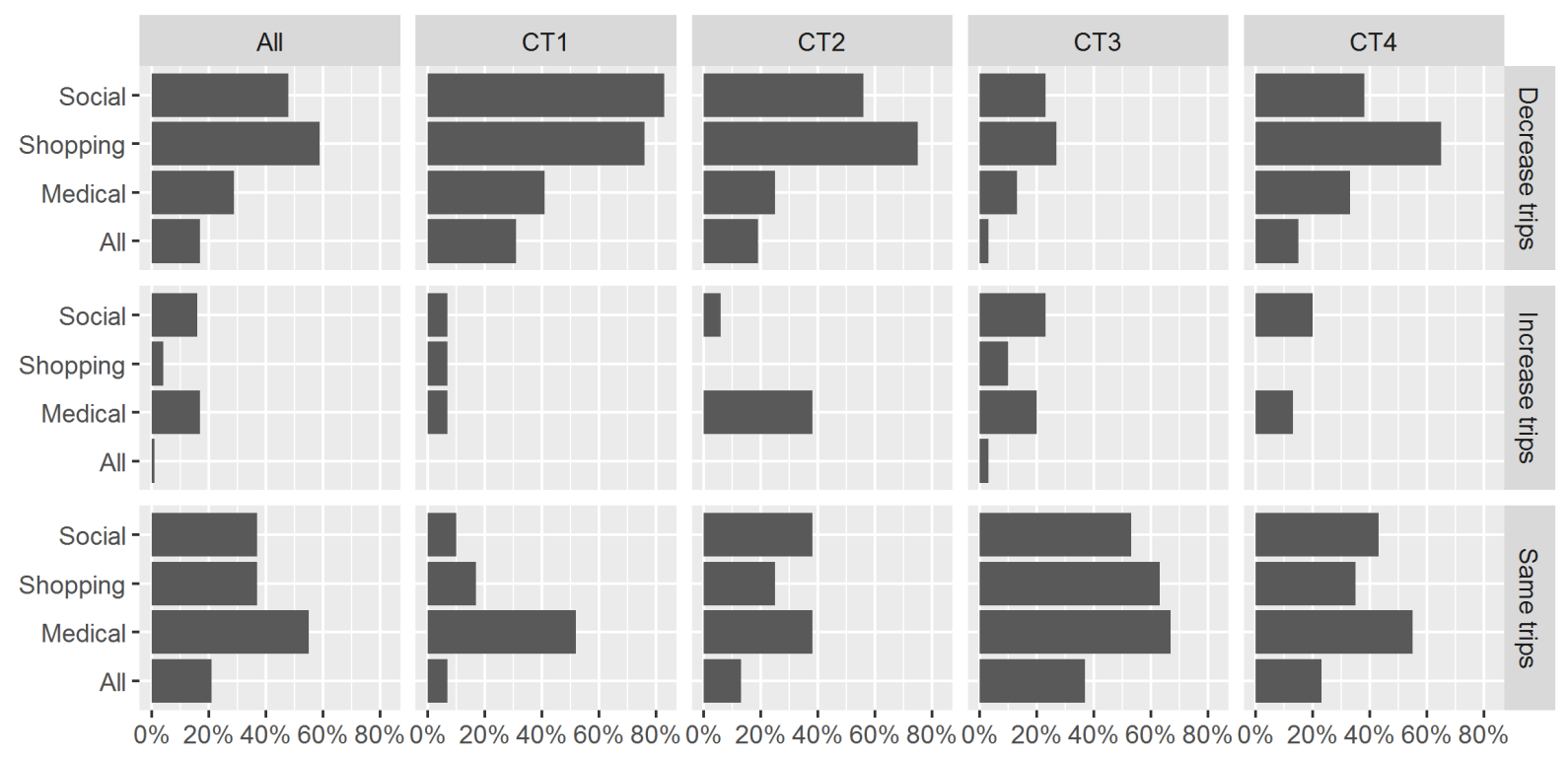

Figure 7: Stated change to trip numbers in response to the proposed PCF scheme

\section{Modelling method}

Given that many respondents want to maintain their current travel patterns, a choice model that can capture the habit effect is used to describe the CT user's choices of what they would do under the proposed PCF scheme ${ }^{1}$. The utility functions of the three options are as follows:

$U_{\text {owntravel }}=a s c_{\text {Own }}$

$U_{\text {mobilityplan }}=\left(1+\beta_{\text {habit_MB }}\right.$ Habit $)\left[\begin{array}{l}\text { asc }_{M B}+\beta_{\text {shop_MB }} \text { ShopTrips }_{M B} \\ +\beta_{\text {med_MB }} \text { MedTrips }_{M B}+\beta_{\text {soc_MB }} \text { SocialTrips }_{M B} \\ +\beta_{\text {subsidy_MB }} \text { Subsidy }_{M B}+\beta_{\text {bundlePR_MB }_{-} \text {BundlePrice }_{M B}}\end{array}\right]$

$U_{\text {payasyougo }}=\beta_{\text {finPay_PG }_{+} \text {FinalPrice }_{P G}}$

Where

$\operatorname{asc}_{M B} \quad=$ Alternative Specific Constant associated with the Mobility Plan

$\operatorname{asc}_{\text {Own }} \quad=$ Alternative Specific Constant Own Travel associated with Own Travel

Habit = Dummy variable, equal 1 if the individual maintains the same number of trips (for each purpose) when given the possibility of designing their own mobility plan, and 0 otherwise.

\footnotetext{
${ }_{1}^{1}$ Possible interactions were tested with the different community transport providers, but they did not show to be statistically significant at a $90 \%$ confidence level. Therefore, these are excluded them from the equations.
} 


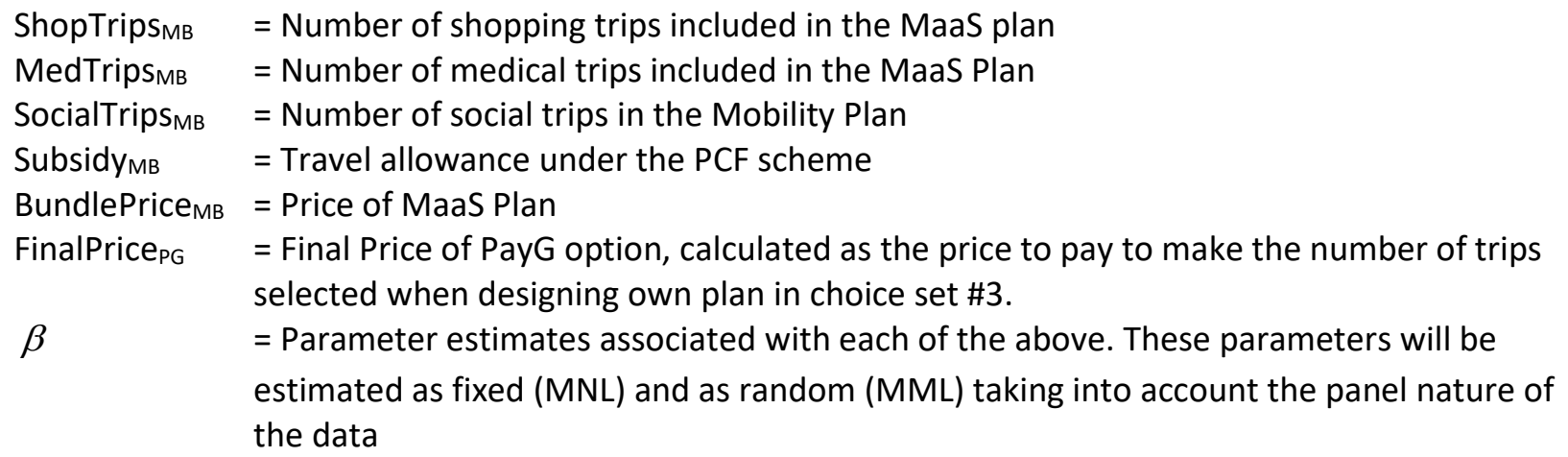

Equation (1) is a form of heteroscedastic conditioning (Hensher \& Ho, 2016). The term in the left-hand-side parenthesis recognises individual circumstances and potential preference heterogeneities. The right-hand-side parenthesis of equation (1) represents the utility function that is explained by the attributes presented in the choice task - which may be positive or negative depending on the choice task characteristics. Therefore, the $\beta_{\text {habit_MB }}$ has to be defined in such a way that is consistent across all scenarios (Balbontin et al., 2019), which is as follows:

$$
\beta_{\text {habit_MB }}= \begin{cases}\beta_{\text {habit_MB }}{ }^{0} & \text { if } U_{\text {iqt }}{ }^{0} \geq 0 \\ -\beta_{\text {habit_MB }}{ }^{0} & \text { if } U_{\text {iqt }}{ }^{0}<0\end{cases}
$$

where

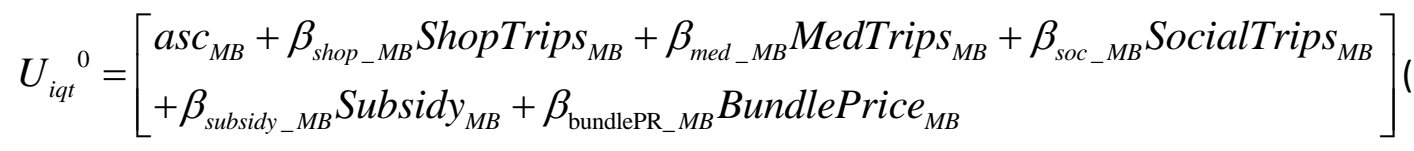

Therefore, a positive $\beta_{\text {habit_MB }}$ would show that respondents who appear to have a trip habit (i.e., who include the same number of trips that they currently undertake when given the possibility to design their own mobility plan) would be more likely to choose the MaaS plan that those who do not have any trip habit. That is, $\beta_{\text {habit_MB }}$ would increase the positive utility $U_{\text {iqt }}{ }^{0}$ (multiplying it by a coefficient larger than 1) and decrease the negative utility (dis-utility) $U_{i q t}{ }^{0}$ (multiplying it by a coefficient between 0 and 1) for those who have a trip habit. A negative $\beta_{\text {habit_MB }}$ would show that individuals with a trip habit would be less likely to choose the MaaS plan alternative. 


\section{Model results}

Table 5 shows the estimation results of the MNL model with fixed parameters and MML model with some parameters specified as random following a normal distribution ${ }^{2}$. All parameters have the expected sign with entitlements having positive parameters and price/cost having a negative parameter. The only exception is the mean annual number of emergency taxi services in the MML model whose parameter is not statistically significant at the $90 \%$ level of confidence. The $\mathrm{MML}$ is significantly superior to the MNL, with a pseudo McFadden $R^{2}$ of 0.59 versus a 0.49 , and an AIC of 1.007 versus a 1.194 of the MNL model. The adopted model rejects the simple MNL model at any reasonable level of significance ${ }^{3}$. Overall, the MML model fits the data quite well, and better than alternatives without habit conditioning so the interpretation and analysis will be focused only in the MML model ${ }^{4}$

The interpretation of model parameters is as follows: a positive parameter estimate suggests a higher likelihood of taking up that option while a negative parameter estimate suggests the opposite. It is also important that the parameter estimate is significant, identified in Table 6 with a star $\left(^{*}\right)$ in the last column (t-value) for different levels of confidence. The model includes some parameters that are not significant at the $90 \%$ level of confidence if they have the expected sign, given the small sample size of 105 respondents. However, most of the parameters are significant at the $80 \%$ level of confidence, which is considered reasonable for this small sample. Moreover, the parameters that are not significant at the $80 \%$ level of confidence represent the mean estimate of an attribute that had a significant standard deviation and thus, should be interpreted together.

Table 5: Model estimation results (all respondents)

\begin{tabular}{ll||rl||rl}
\hline \multirow{2}{*}{ Parameter description } & \multirow{2}{*}{ Option } & \multicolumn{2}{|c}{ MNL } & \multicolumn{3}{c}{ MML } \\
& & Estimate & t-value & Estimate & t-value \\
\hline Bundle price in 2017 \$, mean & MaaS Plan & -0.01 & $-6.79^{* *}$ & -0.07 & $-2.29^{* *}$ \\
Bundle price in 2017 \$, std dev & MaaS Plan & - & - & 0.02 & $2.12^{* *}$ \\
Direct transport subsidy in 2017 \$, mean & MaaS Plan & 0.01 & $3.06^{* *}$ & 0.08 & $2.15^{* *}$ \\
Direct transport subsidy in 2017 \$, std dev & MaaS Plan & - & - & -0.02 & $-1.72^{*}$ \\
Medical trips entitled, mean & MaaS plan & 0.11 & 1.11 & 0.82 & 1.38
\end{tabular}

\footnotetext{
${ }^{2}$ Alternative parameter distributions were tested and the normal distribution appears to be most appropriate considering the parameter estimates and the goodness to fit, measured by the log-likelihood at convergence.

${ }^{3}$ This results is obtained by using the log-likelihood ratio test, where $-2\left(L L_{M M L}-L L_{M N L}\right)=78.51$ which would reject the null hypothesis that the models are equivalent with a $99 \%$ level of confidence.

${ }^{4}$ Two equivalent models to the MNL and MML were estimated without including the habit conditioning parameter. The log-likelihood results are-199.09 and -160.03 respectively. Using the LL ratio test to compare the models with and without conditioning, critical values of 4.12 for the MNL and 4.52 for the MML are obtained. Therefore, the null hypothesis stating that the models are equivalent is rejected with a $95 \%$ confidence level for the MNL and MM Lshowing that the habit conditioning significantly improves the goodness-to-fit of the MNL and MML models.
} 


\begin{tabular}{ll||rl||rl} 
Shopping trips entitled, mean & MaaS plan & 0.09 & 0.98 & 0.74 & 1.43 \\
Shopping trips entitled, std dev & MaaS plan & - & - & 1.48 & $1.83^{*}$ \\
Social trips entitled, mean & MaaS plan & 0.12 & 1.62 & 0.44 & 1.03 \\
Social trips entitled, std dev & MaaS plan & - & - & 0.52 & $1.53^{*}$ \\
Emergency taxi trips entitled, mean & MaaS plan & - & - \\
Emergency taxi trips entitled, std dev & MaaS plan & - & -0.51 & -0.97 \\
Habit & MaaS plan & -0.44 & $-1.53^{*}$ & 0.82 & 1.43 \\
Final price, mean & PayG & 0.00 & $-2.55^{* *}$ & -0.42 & $-1.67^{*}$ \\
Final price, std dev & PayG & - & -0.01 & $-2.02^{* *}$ \\
Constant & MaaS Plan & 1.45 & 2.23 & 0.01 & $1.67^{*}$ \\
Constant & Arrange own & 1.87 & $4.85^{* *}$ & 2.33 & 1.09 \\
& travel & -197.02 & 2.10 & $5.89^{* *}$ \\
\hline LL & & 0.49 & -157.77 \\
McFadden $R^{2}$ & & 1.194 & 0.59 \\
AIC & & 9 & 1.007 \\
Number of estimated parameters & & 16 \\
\hline
\end{tabular}

${ }^{* *}$ Parameter significant at $95 \%$ level of confidence or better and * at $90 \%$ level of confidence.

The results need to be considered for the mean value which gives an average impact, as compared to the standard deviation (std dev) result which gives an indication of whether the preferences for that particular mobility service are broadly similar (i.e., homogenous preference) or substantially different (heterogeneous preferences) across the sampled respondents. For example, the mean parameter of 0.44 associated with the number of social trips included in the MaaS Plan for the MML model suggests that, all else being equal, respondents prefer MaaS plans with more social trips rather than less. However, there is significant heterogeneity across the respondents which is shown by the significant parameter of the standard deviation (0.52) associated with social trips, although the mean estimate is not statistically significant.

The habit variable was statistically significant when conditioning the utility function of the MaaS plan. The negative parameter estimate shows that when an individual maintains their current number of trips when given the possibility of designing their own mobility plan, then they are less likely to choose MaaS alternative. Different scenarios were simulated to show the choice probabilities for different percentage of respondents with a trip habit, and are presented in Table 6. If the percentage of the respondents with a trip habit increases from $21 \%$ to $75 \%$, then the choice probability of the 'MaaS' option would decrease from $17.14 \%$ to $15.51 \%$ and the choice probability of the 'arranging their own travel' option would increase from $81.03 \%$ to $82.63 \%$. This shows that respondents with a trip habit are more likely to choose to arrange their own travel. 
Table 6: Simulated scenarios for different percentage of respondents with a trip habit

\begin{tabular}{|ccc|}
\hline MaaS & PayG & $\begin{array}{c}\text { Arrange } \\
\text { own } \\
\text { travel }\end{array}$ \\
\hline $17.39 \%$ & $1.82 \%$ & $80.78 \%$ \\
\hline $17.14 \%$ & $1.83 \%$ & $81.03 \%$ \\
\hline $16.34 \%$ & $1.85 \%$ & $81.81 \%$ \\
\hline $15.51 \%$ & $1.87 \%$ & $82.63 \%$ \\
\hline
\end{tabular}

\section{Estimation of willingness to pay}

Estimating individuals willingness to pay (WTP) for a product or service is critical for developing strategies, particularly for new 'products'. WTP is the highest price which an individual is prepared to pay for a 'unit' of a product or service. Whilst this in practice is a single value for each person, it is shown here as a mean and confidence intervals (percentile $5 \%$ and $95 \%$ ) because WTP is estimated from a sample of respondents. The importance of the WTP for CT providers is that it provides a ceiling for pricing the elements within a MaaS bundle and is an important part of future strategy.

The WTP of interest refer to the MaaS plan alternative. These are estimated as the quotient between an attribute, $x_{M B}$, marginal (dis)utility and the marginal (dis)utility of the cost. The marginal (dis)utilities are calculated as the derivative of the utility function relative to the attribute as shown in equation (3).

$$
W T P_{x_{M B}}=\frac{\partial U_{\text {mobilityplan }} / \partial x_{M B}}{\partial U_{\text {mobilityplan }} / \partial \operatorname{Cost}_{M B}}
$$

The MaaS plan cost was presented with two attributes: the bundle price and a direct transport subsidy. Both are considered to calculate the cost marginal (dis)utility using a weighted average. The subsidy and the price have an opposite impact on the utility function - i.e., positive and negative, respectively - so this has to be taken into account in the weighted average as follows:

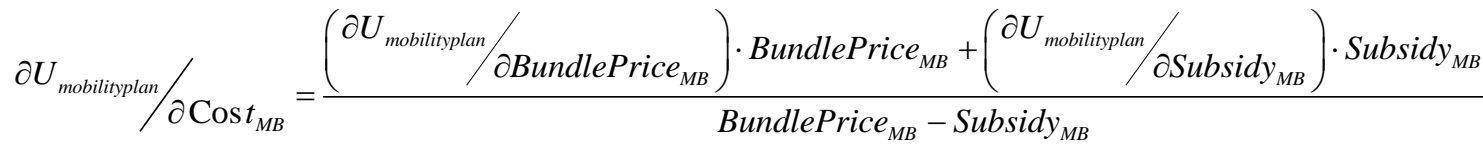


The WTP mean and confidence intervals were estimated using PythonBiogeme (Bierlaire, 2016), which allows us to use simulation to run a sensitivity analysis taking into account the variance covariance matrix ${ }^{5}$. The WTP, estimated from the parameters shown in Table 5, are presented in Table 7.

Table 7: Estimates of CT user's WTP for MaaS plan

\begin{tabular}{lrrr}
\hline WTP for entitlement of one trip in monthly MaaS plan & \multicolumn{3}{c}{ MML model } \\
& Mean & $\mathbf{5 \%}$ & \multicolumn{1}{c}{$\mathbf{9 5 \%}$} \\
\hline Medical trip & $\$ 13.84$ & $-\$ 26.45$ & $\$ 53.65$ \\
Shopping trip & $\$ 8.16$ & $-\$ 61.96$ & $\$ 84.92$ \\
Social trip & $\$ 6.97$ & $-\$ 28.46$ & $\$ 42.96$ \\
Annual emergency taxi services & $-\$ 9.14$ & $-\$ 67.67$ & $\$ 48.46$ \\
\hline
\end{tabular}

On average, the respondents are willing to pay around $\$ 13.84$ to have one medical trip included in their monthly MaaS plan, while the WTP estimates for shopping and social trip are $\$ 8.16$ and $\$ 6.97$, respectively. The parameter associated with emergency taxi trips is not statistically significant, so the mean estimate is not very meaningful on its own but only with the confidence intervals. It can be seen that the WTP lower bound for all the types of trips is negative; showing that a part of the respondents would rather not have those trips included in their bundle. Oppositely, the highest bound shows that some individuals are willing to pay significantly more than the mean to include these trips in their bundles.

It should be noted that these WTPs are additive. For example, a monthly bundle that provided two shopping trips, one social trip and one medical trip has an average WTP of $\$ 37.13(2 \times 13.84+8.16+$ $6.97=37.13)$. If this bundle is priced at $\$ 37.13$ per month, the model estimates that $50 \%$ of the CT clients would find it appealing (and would subscribe to MaaS offers) while the remaining $50 \%$ of the CT clients would not. Without exception, the average WTP estimates are much smaller than the unit cost of providing the services, as identified by a separate discussion with the participating $\mathrm{CTs}^{6}$. This will present a real challenge for all CT providers under a PCF and is a significant factor in developing MaaS packages for CT users.

\section{Discussion and Conclusion}

This paper examines the willingness to pay for bundles of mobility services, in light of the possibility of potential funding changes to the regime that currently supports community transport in

\footnotetext{
${ }^{5}$ The reader is referred to (Bierlaire, 2016) for more information on the sensitivity analysis. 500 draws have been used for the sensitivity analysis simulations.

${ }^{6}$ Due to commercial confidentiality reasons, the unit costs cannot be reported in this paper.
} 
Australia.. In this Australian context, as the literature context makes clear, CT providers remain critical to helping vulnerable clients get out and about, and even in a PCF scenario were identified as the preferred transport provider for respondents, particularly for medical trips. The research is therefore timely as a way of investigating whether MaaS bundling might be a useful response for CT providers to offer certainty to their existing clients as the funding system changes.

The research underpinning this paper creates a link between what the respondents do now, as CT clients, and what they may choose to do in the future under a PCF scenario with a MaaS concept presented for adoption. Clients here are broadly in line with the characteristics identified in the literature context in that they are non car drivers and do not tend to frequent public transport. The MaaS bundle was presented to respondents as a way of packaging their mobility needs to provide certainty for their delivery. For CT providers, the bundles provided an opportunity to have a planning horizon with a better idea of how many trips might be demanded from the pre-booked bundles. The CT provider in this context would be acting not only as a provider of transport services but also as the broker or intermediary, procuring services from other providers as demanded by the CT clients. In discussion about the hypothetical future in the stated choice survey process, the respondents understood that the new PCF enviornment might involve changes to their travel patterns and the cost of that travel to them when subsidy is removed.

In terms of results, when WTP was examined, the analysis showed the estimates were much smaller than the unit costs of providing the service, posing a challenge for CT providers. On average, the respondents are estimated to be willing to pay $\$ 13.84$ for a medical trip, $\$ 8.16$ for a shopping trip and $\$ 6.97$ for a social trip (all round trips) in the unsubsidised world of PCF. These WTP figures are substantially lower than the unit costs of provision. So, whilst the MaaS concept potentially provides CT users with the autonomy to arrange their own travel as well as providing a level of patronage predictability for the CT providers when CT users subscribe to a mobility bundle, the issue of low WTP is a serious obstacle to overcome. As an example, a monthly mobility bundle of two group shopping trips, one group social outing and one individual medical trip with $10 \mathrm{~km}$ each way would cost the CT at least $\$ 100$ to provide but an average willingness to pay for this bundle is only $\$ 37.13$. This suggests that the possible transition to PCF will not be an easy process requiring significant education as to the cost of provision with MaaS bundles as an option based on the rich data gathered from the CAPI (and associated analysis and commentary) to help CT providers make informed decisions moving forward.

Existing clients of CT in Australia, as reflected by the sample on which this research is based, are unlikely to find conventional public transport their basic mobility service due to the effort and 
knowledge required for the use of these services such as walking to and from bus stops/train stations. One transition from the status quo to a PCF environment which could include a wider role for CT providers than at present would be for the $\mathrm{CT}$ to transform into a mobility manager function, particularly for clients who may not be so aged or as frail. In this role, CT providers, in addition to providing door to door services for clients they provide through a subscription, would provide or negotiate the all-round mobility for new clients who may not be as aged or as frail. This all round mobility could include taxi services, car share and other shared mobility options. This could be extended to existing clients who are less mobility challenged. As a mobility manager, the CT providers could use their own vehicles to provide services when there is spare capacity or use the 'bulk purchasing' leverage to negotiate discounts with, for example, local taxi firms. A factor very much in favour of this as a successful business strategy is that CT providers are well placed to know their client's needs and CT providers are familiar with the issues arising from a client base where the smart phone penetration is lower than average.

There are still many unanswered questions as to whether using some variant of a subscription model could be a way of tying in CT clients to provide the mutual benefit of mobility security for clients and a more secure planning horizon for CT providers. In particular, future research needs to consider the next generation of potential CT users to see if they maybe 'captured' early with a CT MaaS subscription targeting key life change points such as ceasing to drive a car. Of course, the future will also be affected by the changing experiences of citizens who become CT clients. Future clients are certainly likely to be more technologically experienced and, depending on the development of MaaS schemes elsewhere, may be much more familiar with MaaS bundles and what these might offer. Future clients might therefore make quite different choices from the cohort of respondents in this research.

All papers have limitations and a limitation of this research is the evidence comes only from four CT providers with a relatively small overall sample size of 105: the results must be considered as preliminary and exploratory. However, the sample when segmented by CT providers showed sufficient variation to make it clear that a CT provider wanting to develop MaaS bundles or wanting to expand into greater mobility management will need to interrogate their operating territory in some detail before stepping out to make the change. 


\section{Acknowledgements}

This research of this paper has been made possible through an industry partnership grant between the Business School at the University of Sydney, Australia and the Community Transport partners. We are

grateful for this support and for the support of their clients, our respondents. We are also grateful for the anonymous comments of reviewers who have enabled us to improve the paper.

\section{References}

Age UK. (2012) 'Older people travel the most'. Retrieved on August 272018 from

http://www.ageuk.org.uk/latest-news/archive/older-people-travel-the-most/

Alsnih, R., \& Hensher, D.A. (2006). The mobility and accessibility expectations of seniors in an aging population. Transportation Research Part A: Policy and Practice, 37(10), 903-916.

Balbontin, C., Hensher, D.A., \& Collins, A.T. (2019) Process homogeneity, process heterogeneity, and preference heterogeneity: How to better represent decision making and preferences. Transportation Research Part B: Methodological, 122, 218-248.

Bierlaire, M. (2016). PythonBiogeme: a short introduction. Report TRANSP-OR 160706, Series on Biogeme. Transport and Mobility Laboratory, School of Architecture, Civil and Environmental Engineering, Ecole Polytechnique Fédérale de Lausanne, Switzerland.

Browning, C., \& Sims, J. (2007). Ageing without driving: Keeping older people connected'. In Currie, G., Stanley, J., \& Stanley., J. (Eds). No way to go: Transport and social disadvantage in Australian communities (pp. 6.1-6.10). Melbourne: Monash University ePress.

Choice Metrics. (2012). NGene. Choice Metrics, Sydney.

Colombo, F., Ana, L., Jerome, M., \& Frits, T. (2011). Help wanted? Providing and paying for long-term care. OECD Publishing, Paris.

Department for Transport. (2016). Statistical Release, National Travel Survey 2015. Retrieved on August 272018 from https://assets.publishing.service.gov.uk/government/uploads/system/uploads/attachment data/file/5 51437/national-travel-survey-2015.pdf

Goodwin, P., \& Van Dender, K. (2013). 'Peak car' -Themes and issues. Transport Reviews, 33(3), 243-

254. 
Harris, A., \& Tapsas, D. (2006). Transport and mobility: Challenges, innovations and improvements. Melbourne: Royal Automobile Club of Victoria (RACV)

Hensher, D. A., \& Ho, C. Q. (2016). Experience conditioning in commuter modal choice modelling Does it make a difference? Transportation Research Part E: Logistics and Transportation Review, 95, 164-176.

Hensher, D. A., Rose, J. M., \& Greene, W. H. (2015) Applied choice analysis (2 ${ }^{\text {nd }}$ Edition). Cambridge University Press. London, England.

Hietanen, S. (2014). 'Mobility as a service' - the new transport model?. Eurotransport, 12(2), 2-4.

Ho, C., Hensher, D., Mulley, C., \& Wong, Y. (2018) Potential uptake and willingness-to-pay for Mobility as a Service (MaaS): A stated choice study. Transportation Research Part A, 117, 302-318.

Gatta, V. \& Marcucci, E. (2016) Stakeholder-specific data acquisition and urban freight policy evaluation: evidence, implications and new suggestions. Transport Reviews, 36, 585-609.

Lyngby, Denmark. Socher, J and Sarasini, S V (2017) Users' motives to adopt and willingness to pay for Mobility as a Service. Proc. 137ICoMaaS 2017. Retrieved on August 272018 from http://www.tut.fi/verne/aineisto/ICoMaaS Proceedings S4.pdf

Lynott, J., \& Figueiredo, C. (2011). How the travel patterns of older adults are changing: Highlights from the 2009 national household travel survey. Fact Sheet 218, April, 2011 AARP Public Policy Institute, 601 E Street, NW, Washington, DC 20049.

Mackett, R. (2014). Overcoming the barriers to access for older people. Centre for Transport Studies, UCL. Contribution to the Transport Working Group of the Age Action Alliance (AAA).

Mulley, C., \& Nelson, J. D. (2012). Recent developments in community transport provision: Comparative experience from Britain and Australia. Procedia- Social and Behavioral Sciences, 48, 1815-1825.

Mulley, C., \& Kronsell, A. (2018). Workshop 7 report: The "uberisation" of public transport and mobility as a service (MaaS): Implications for future mainstream public transport. Research in Transportation Economics, 69, 568-572.

Musselwhite, C. (2011) Successfully giving up driving for older people. Discussion Paper. International 
Longevity Centre - UK. Available from: http://eprints.uwe.ac.uk/16246

Nomura, M., \& Takahashi, Y. (2017). 'Uberisation in rural Japan: A case of community transport in Tango

Peninsula, Kyoto Prefecture'. International Conference Series on Competition and Ownership in Land

Passenger Transport - 2017 - Stockholm, Sweden - Thredbo 15.

Plazinic, B., \& Jovic, J. (2018). Mobility and transport potential of elderly in differently accessible rural areas. Journal of Transport Geography, 68, 169-180.

Rose, J. M., \& Bliemer, M. C. J. (2013). Sample size requirements of stated choice experiments.

Transportation, 40, 1021-1041.

Rose, J. M., \& Bliemer, M. C. J. (2006). Designing efficient data for stated choice experiments. Paper presented at the 11th international conference on Travel Behaviour Research, Kyoto, Japan.

Rosenbloom, S., \& Morris, J. (1998). Travel patterns of older Australians in an international context: Policy implications and options. Transportation Research Record, 1617, 189-193.

Rosenbloom, S. (2001). Sustainability and automobility among the elderly: An international assessment. Transportation, 28(4), 375-408.

Rosenbloom, S. (2009). Meeting transportation needs in an aging-friendly community. Generations Journal of the American Society on Ageing, 33(2), 33-43.

Shergold, I., Lyons, G., \& Hubers, C. (2015). Future mobility in an ageing society - Where are we heading? Journal of Transport \& Health, 2 (1), 2015, 86-94.

Siren, A. K., \& Haustein, S. (2012). Cohort analysis of older adults' travel patterns in Denmark. Department of Transport, Bygningstorvet 116B, 2800 Kgs. Suen, S.L., \& Sen, L. (2004). Mobility options for seniors. In Transportation in an aging society: A decade of experience, Technical papers and reports from a conference, November 7-9, 1999, Bethesda, Maryland, 97-113. Washington DC: Transportation Research Board.

Transport Research Centre (1994-1999_, Victorian Activity and Travel Survey (VATS), Melbourne. 
Transport Systems Catapult. (2016). Older travellers and technology engagement. Retrieved on August 272018 from https://s3-eu-west-1.amazonaws.com/media.ts.catapult/wpcontent/uploads/2017/04/03094002/TSC-Older-Travellers-Technology-Engagement-ReportMarch-17.pdf

Zeitler, E., \& Buys, L. (2015). Mobility and out-of-home activities of older people living in suburban environments: 'Because I'm a driver, I don't have a problem'. Ageing and Society, 35(4), 785808. 